\title{
Determinants of smoking cessation and abstinence in a Russian smoking-cessation center
}

\author{
Vladimir Levshin' ${ }^{7}$ Nina Slepchenko
}

\begin{abstract}
INTRODUCTION Smoking prevalence in Russia is one of the highest in the world. It leads to significant damage to the National Health Service. The purpose of the present research was to assess the effectiveness of a qualified smoking-cessation (SC) center in Moscow, and to identify the main determinants of smoking cessation.

METHODS The subjects of this study were a cohort of smokers $(n=524)$ who had attended the SC service in Moscow between 2012-2015. They were followed, for at least 6 months after receiving the professional counselling in smoking cessation, to assess the results of the assistance and to identify determinants of successful smoking cessation.

RESULTS Of the smokers, $19 \%$ succeeded in reducing by more than half the number of smoked cigarettes, more than $46 \%$ of patients completely stopped smoking for different terms: $38 \%$ for more than a month and $24 \%$ for more than half a year. Odds ratios (ORs) indicated that the probability of successful smoking cessation significantly increased if there was a previous success in smoking cessation: OR 3.71 (95\% CI 1.70-8.12); and if there was a high level of motivation to stop smoking OR 4.3 (95\% CI 1.92-5.61). The probability of successful smoking cessation decreased with intensity of smoking > 10 cigarettes a day: OR 0.57 (95\% CI 0.31-1.02); and an elevated (>7 points) Fagerström-test score OR 0.64 (95\% CI 0.37-1.07).

conclusions Degree of motivation and willingness to quit smoking were the principal determinants of the effectiveness in the attempt to quit smoking within our study cohort.
\end{abstract}

\section{AFFILIATION \\ 1 Russian Cancer Research \\ Center of N. N. Blochin, Russia \\ CORRESPONDENCE TO \\ Vladimir Levshin. Russian Cancer Research Center, Kashirskoye sh. 24, Moscow -115478, Russia. \\ E-mail: levshin_vladimir@mail.ru \\ KEYWORDS \\ smoking cessation, determinants, tobacco addiction}

Received: 6 February 2017
Revised: 7 July 2017 Accepted: 23 August 2017

\section{INTRODUCTION}

Tobacco smoking is one of the leading causes of death amongst the world population. Currently, smoking is related to approximately $20 \%$ of total adult mortality in 63 countries overall ${ }^{1}$. Smoking prevalence in Russia, where about $60 \%$ of men and $21 \%$ of women smoke ${ }^{2}$, is one of the highest in the world. Thus, tobacco smoking leads to great damage in the National Health Service. Smoking is estimated to cause more than $17 \%$ of all deaths in Russia ${ }^{3}$. Other studies by Russian authors $^{4}$ showed that $43 \%$ of deaths from cancer tumors in men, age $35-69$ years, and $89 \%$ of all deaths from lung cancer, were attributable to smoking. At the same time, while in most of the developed countries smoking prevalence for the last 20-30 years has considerably decreased, in Russia there has been little change. The reason is the lack of effective anti-smoking measures and programs. Only by the end of 2013 the Federal law 'About Protection of Health of the Population against Tobacco Consumption Consequences' was adopted, which provides for the implementation of a complex of educational, administrative, economic and medical anti-smoking measures ${ }^{5}$.

It should be noted that tobacco-control laws and programs work effectively only when a whole package of measures is implemented $^{6}$. It is not productive to give priority to some measures to the detriment of others. The majority of regular smokers suffer from tobacco addiction (TA), which is a serious obstacle to smoking cessation (SC) for patients who would like to stop smoking. Therefore, one of the main directions of the tobacco-control program is development and implementation of qualified and effective forms of SC counselling (SCC) through the health-care system. 
Development of effective methods of SC should be conducted with an objective assessment of their efficiency. Tobacco addiction is a chronic disorder that has a high potential for relapse. Therefore, the majority of tobacco users who stop smoking for a short period (several days, weeks and even a month) often relapse ${ }^{7}$. Hence the main condition for objective assessment of efficiency of any SC method or assistance, is a long follow-up period after cessation needed to obtain the objectives of SC.

Furthermore, it is quite important for the development of SCC to identify the factors that have significant influence on the results of SC. Considering such factors as predictors or determinants of SC outcomes may help to provide a more rational and effective SCC.

The main aim of this study was to investigate and evaluate the effectiveness and determinants of successful smokingcessation methods.

\section{METHODS}

\section{Setting and participants}

The subjects of this study were a cohort of smokers who had attended the SCC in Moscow during a 3-year period (20122014). The service was organized within the premises of the Department of Prevention of the Russian Cancer Research Center. The promotion campaign was arranged in some local mass-media to provide information about the service, in order to invite current smokers wishing to quit smoking. Also, the announcement about the SCC was put up in the reception areas of 14 out-patient clinics. The study was approved by the ethics committee of the Russian Cancer Research Center. The number of patients who attended the smoking-cessation service and received the intervention during the 3-year period was 602 . But only 524 patients who were available for monitoring during at least six months after the SCC were included in the study. However, 78 patients who followed the SC program could not be contacted to confirm their cessation status at 6 months follow up, due to a change in phone, residence or other reasons. These patients were excluded from the study. Thus, we had a $13 \%$ loss in patients for the follow-up.

\section{Procedure}

Before receiving professional SCC, all smokers underwent a special examination, including: registration, recording of demographic data, carbon monoxide (CO) levels, and filling in the structured questionnaire concerning their smoking history and present status. The Fagerström test ${ }^{7}$ was used to assess TA degree and a special test ${ }^{8}$ was carried out to determine the level of motivation to stop smoking. After the examination
SC therapy was provided. It included a short lecture aimed to strengthen the motivation to stop smoking by informing them about tobacco intoxication, TA and the short- and long-term dangerous consequences if they continued smoking. SCC also included the instruction regarding behavioral techniques for SC, and recommendation of medication to control or decrease TA and abstinence-syndrome treatment. The following drugs registered in the country were recommended: nicotine replacement therapy (NRT), varenicline and cytizin (Tabex). Individual indications and contraindications were taken into account while prescribing these medicines. The entire counselling process included a follow-up observation arranged through patients' repeated visits and more often through contacts with them by phone.

Follow-up contacts by phone were made at 1, 3, 6 and 12-month periods after SCC. During the contact, it was clarified: whether there had been any attempt to stop smoking, what was the result of such an attempt, and which recommendations of the smoking-cessation procedure had been adopted. If the attempt to stop smoking was unsuccessful repeated consultation and further methods were offered for the correction of the individual's SC status. In case of a relapse, assistance was also offered and provided.

\section{Statistical analysis}

To define characteristics that significantly predict smoking cessation, various outcomes of SCC were combined into two main indicators of the result: 'positive' and 'negative'. All patients who managed to stop smoking for 1 month or more were designated as having achieved a positive result. All patients with other results; including patients who stopped smoking for short terms (less than a month), patients who smoked intermittently and those who made no attempt to stop smoking, were designated as having achieved a negative result. Such division was used for the analysis of the association between different personal characteristics and SCC result by calculation of the odds ratio (OR) at $95 \%$ confidence interval (CI).

The following factors were analyzed to find out their possible influence on SCC results and effectiveness: gender, age, intensity and duration of smoking, TA degree, existence and effectiveness of prior experience of SC, level of motivation and readiness to stop smoking, and adherence to SCC recommendations. Material for research and analysis were the data obtained at the smokers' baseline examination and SCC results found at 6 months or more follow-up with assessment of the smoking status. Descriptive statistics, chi-square test, and unadjusted odds ratio (OR) at $95 \%$ confidence interval 
(CI) were used to compare groups with different SCC results, and to identify factors that could be associated with the SCC outcomes.

\section{RESULTS}

Data on age and sex structure of 524 patients included in the study, and data on SCC results, are presented in Table 1. The age varied between 18 and 75 years. The percent of patients aged up to 30 years was $17.6 \%$, from 30 to 49 years was $43.9 \%$, and aged 50 years and more was $38,5 \%$. The percent of men and women in the study cohort were $60 \%$ and $40 \%$, respectively.

The analysis of the data of the SCC results in the cohort study (Table 1) shows that out of the total number of the smokers $(n=524)$ who received SCC, $15 \%$ of men and $16 \%$ of women had not even attempted to change their smoking behaviour afterwards. Special interviews of these patients showed that the main reasons for the lack of attempt to stop smoking after the SCC were: postponement of the attempt to a future time, disbelief in the efficiency of the offered methods of SC, a change of the decision to stop smoking (data not shown).

The majority of smokers $443(84.5 \%)$ made quit attempts after SCC with different outcomes. The percentage of patients with no result after the quit attempt in the age group $<30$ years old, for both genders, was significantly less than in the age group 50 years or more; $14.1 \%$ and $24.3 \%$, respectively ( $p$
$<0.05)$. Most smokers $(342,65.3 \%)$ achieved some positive results, while 100 (19,1\%) patients succeeded to cut down the number of smoked cigarettes per day by half or more. The number of patients who stopped smoking completely for periods: less than a month, 1-6 months and more than 6 months, were 42 (8\%), 76 (14.5\%) and 124 (23.7\%), respectively. The percentage of men who achieved more than 1-month abstinence was higher than the corresponding percentage of women, $41.7 \%$ and $33.8 \%$, respectively, $\mathrm{p}=0.05$. It should be noted that amongst men up to 30 years old $43.6 \%$ stopped smoking for more than a month, and for men 50 years old or more $31.2 \%, \mathrm{p}>0.05$.

The assessment of the SCC results association with the duration of regular smoking in years (Table 2) shows that in comparison with patients with minimal duration of smoking (1-9 years), the probability to achieve a positive result of SCC was three times more for patients with 10-19 years duration of smoking, OR 3.12 (95\% CI 1.58-6.15), and two times more for patients with 20-29 years duration of smoking, OR 1.97 (95\% CI 0.97-3.97).

Data on assessment of association of SCC results with the intensity of smoking measured by the number of the cigarettes smoked per day (Table 2 ) show that the probability of a positive result of SCC decreased in the group of patients who smoked more than 10 cigarettes per day as compared to the group of patients who smoked no more than 10 cigarettes per day, OR 0.59 (CI 0.33-1.03).

Table1. Results ofSCCamong 524 adult regularsmokers, Moscow 2012-2014

\begin{tabular}{|c|c|c|c|c|c|c|c|c|}
\hline \multirow[t]{3}{*}{ GENDER } & \multirow[t]{3}{*}{ AGE years } & \multirow[t]{3}{*}{$\mathbf{N}(\%)$} & \multirow[t]{3}{*}{ Voattempt } & \multirow{3}{*}{$\begin{array}{l}\text { Attempt } \\
\text { without } \\
\text { any effect }\end{array}$} & \multicolumn{3}{|c|}{ Outcome of $\mathrm{SCC}^{*}$} & \\
\hline & & & & & \multirow{2}{*}{$\begin{array}{c}\text { Cut down } \\
\text { number cigs/day }\end{array}$} & \multicolumn{3}{|c|}{ Quit-smoking duration in months } \\
\hline & & & & & & $<1$ & $1-6$ & $>6$ \\
\hline \multirow{4}{*}{ MEN } & $<30$ & $\begin{array}{c}39 \\
(100 \%)\end{array}$ & $\begin{array}{c}8 \\
20.5 \%\end{array}$ & $\begin{array}{c}5 \\
12.8 \%\end{array}$ & $\begin{array}{c}7 \\
18.0 \%\end{array}$ & $\begin{array}{c}2 \\
5.1 \%\end{array}$ & $\begin{array}{c}7 \\
18.0 \%\end{array}$ & $\begin{array}{c}10 \\
25.6 \%\end{array}$ \\
\hline & $30-49$ & $\begin{array}{c}129 \\
(100 \%)\end{array}$ & $\begin{array}{c}15 \\
11.6 \%\end{array}$ & $\begin{array}{c}20 \\
15.5 \%\end{array}$ & $\begin{array}{c}20 \\
15.5 \%\end{array}$ & $\begin{array}{c}8 \\
6.2 \%\end{array}$ & $\begin{array}{c}28 \\
21.7 \%\end{array}$ & $\begin{array}{c}38 \\
29.5 \%\end{array}$ \\
\hline & $>49$ & $\begin{array}{c}125 \\
(100 \%)\end{array}$ & $\begin{array}{c}21 \\
16.8 \%\end{array}$ & $\begin{array}{c}29 \\
23.2 \%\end{array}$ & $\begin{array}{c}26 \\
20.8 \%\end{array}$ & $\begin{array}{c}10 \\
8.0 \%\end{array}$ & $\begin{array}{c}13 \\
10.4 \%\end{array}$ & $\begin{array}{c}26 \\
20.8 \%\end{array}$ \\
\hline & All ages & $\begin{array}{c}293 \\
(100 \%)\end{array}$ & $\begin{array}{c}44 \\
15 \%\end{array}$ & $\begin{array}{c}54 \\
18.4 \%\end{array}$ & $\begin{array}{c}53 \\
18.1 \%\end{array}$ & $\begin{array}{c}20 \\
6.8 \%\end{array}$ & $\begin{array}{c}48 \\
16.4 \%\end{array}$ & $\begin{array}{c}74 \\
25.3 \%\end{array}$ \\
\hline \multirow{4}{*}{ WOMEN } & $<30$ & $\begin{array}{c}53 \\
(100 \%)\end{array}$ & $\begin{array}{c}7 \\
13.2 \%\end{array}$ & $\begin{array}{c}8 \\
15.1 \%\end{array}$ & $\begin{array}{c}8 \\
15.1 \%\end{array}$ & $\begin{array}{c}9 \\
17.0 \%\end{array}$ & $\begin{array}{c}7 \\
13.2 \%\end{array}$ & $\begin{array}{c}14 \\
26.4 \%\end{array}$ \\
\hline & $30-49$ & $\begin{array}{c}101 \\
(100 \%)\end{array}$ & $\begin{array}{c}16 \\
15.8 \%\end{array}$ & $\begin{array}{c}19 \\
18.8 \%\end{array}$ & $\begin{array}{c}25 \\
24.8 \%\end{array}$ & $\begin{array}{l}10 \\
9.9 \%\end{array}$ & $\begin{array}{c}11 \\
10.9 \%\end{array}$ & $\begin{array}{c}20 \\
19.8 \%\end{array}$ \\
\hline & $>49$ & $\begin{array}{c}77 \\
(100 \%)\end{array}$ & $\begin{array}{c}14 \\
18.2 \%\end{array}$ & $\begin{array}{c}20 \\
26 \%\end{array}$ & $\begin{array}{c}14 \\
18.2 \%\end{array}$ & $\begin{array}{l}3 \\
3.9 \%\end{array}$ & $\begin{array}{c}10 \\
13.0 \%\end{array}$ & $\begin{array}{c}16 \\
20.7 \%\end{array}$ \\
\hline & All ages & $\begin{array}{c}231 \\
(100 \%)\end{array}$ & $\begin{array}{c}37 \\
16 \%\end{array}$ & $\begin{array}{c}47 \\
20.3 \%\end{array}$ & $\begin{array}{c}47 \\
20.3 \%\end{array}$ & $\begin{array}{c}22 \\
9.5 \%\end{array}$ & $\begin{array}{c}28 \\
12.1 \%\end{array}$ & $\begin{array}{c}50 \\
21.7 \%\end{array}$ \\
\hline TOTAL & & $\begin{array}{c}524 \\
(100 \%)\end{array}$ & $\begin{array}{c}81 \\
15.5 \%\end{array}$ & $\begin{array}{c}101 \\
19.3 \%\end{array}$ & $\begin{array}{c}100 \\
19.1 \%\end{array}$ & $\begin{array}{c}42 \\
8.0 \%\end{array}$ & $\begin{array}{c}76 \\
14.5 \%\end{array}$ & $\begin{array}{c}124 \\
23.7 \%\end{array}$ \\
\hline
\end{tabular}

${ }^{*} \mathrm{SCC}=$ Smoking cessation counselling, cigs=cigarettes 
Table 2. Association assessment between different characteristics of smokers and SCC result, Moscow 20122014

\begin{tabular}{|c|c|c|c|c|}
\hline \multirow{2}{*}{ FACTORS } & \multirow[t]{2}{*}{ Number of patients } & \multicolumn{3}{|c|}{ SCCresults } \\
\hline & & Positive & Negative & $\mathrm{R}(95 \% \mathrm{Cl})$ \\
\hline \multicolumn{5}{|l|}{ Smoking duration in years } \\
\hline $1-9$ & 61 & 15 & 46 & 1.0 \\
\hline $10-19$ & 121 & 61 & 60 & $3.12(1.58-6.15)$ \\
\hline $20-29$ & 128 & 50 & 78 & $1.97(0.97-3.97)$ \\
\hline$>29$ & 214 & 74 & 140 & $1.62(0.83-3.15)$ \\
\hline \multicolumn{5}{|l|}{ Smoking intensity cgs/day } \\
\hline$\leq 10$ & 56 & 28 & 28 & 1.0 \\
\hline $11-20$ & 293 & 106 & 187 & $0.57(0.31-1.02)$ \\
\hline $21-30$ & 41 & 16 & 25 & $0.64(0.27-1.53)$ \\
\hline$>30$ & 134 & 51 & 83 & $0.61(0.32-1.18)$ \\
\hline \multicolumn{5}{|l|}{ TA - Fagerström test score } \\
\hline $1-4$ & 88 & 41 & 47 & 1.0 \\
\hline $5-7$ & 241 & 90 & 151 & $0.68(0.41-1.14)$ \\
\hline$>7$ & 195 & 69 & 126 & $0.63(0.37-1.07)$ \\
\hline \multicolumn{5}{|l|}{ Previous quit experience } \\
\hline No quit attempt & 41 & 9 & 32 & 1.0 \\
\hline Quit attempt without result & 203 & 53 & 150 & $1.26(0.55-2.89)$ \\
\hline Could cut down the number of cigs & 51 & 21 & 30 & $2.49(0.96-6.47)$ \\
\hline Could stop smoking for some period & 229 & 117 & 112 & $3.71(1.70-8.12)$ \\
\hline \multicolumn{5}{|l|}{ Level of motivation to stop smoking } \\
\hline$<12$ & 52 & 8 & 44 & 1.0 \\
\hline $12-13$ & 130 & 43 & 87 & $2.72(1.15-6.45)$ \\
\hline $14-15$ & 219 & 95 & 124 & $4.21(1.88-9.43)$ \\
\hline$>15$ & 123 & 54 & 69 & $4.30(1.85-10.00)$ \\
\hline
\end{tabular}

Table 3. Association assessment between smokers'adherence to the SCC recommendations and prescriptions and SCC results, Moscow 20122014.

\begin{tabular}{|c|c|c|c|c|c|}
\hline \multirow[t]{3}{*}{ Adherence to recommendations } & \multirow[t]{3}{*}{ Number of patients } & \multicolumn{4}{|c|}{ SCCresults } \\
\hline & & \multirow{2}{*}{$\begin{array}{l}\text { Could not } \\
\text { stop smoking }\end{array}$} & \multicolumn{3}{|c|}{ Quit-smoking duration in months } \\
\hline & & & $<1$ & $1-6$ & $>6$ \\
\hline not carrying out & 49 & 28 & 7 & 6 & 8 \\
\hline any recommendation & $100 \%$ & $57.2 \%$ & $14.3 \%$ & $12.2 \%$ & $16.3 \%$ \\
\hline used only & 92 & 49 & 6 & 10 & 27 \\
\hline behavioral approaches & $100 \%$ & $53.3 \%$ & $6.5 \%$ & $10.9 \%$ & $29.3 \%$ \\
\hline used only prescribed & 134 & 64 & 12 & 27 & 31 \\
\hline medicine & $100 \%$ & $47.8 \%$ & $9.0 \%$ & $20.1 \%$ & $23.1 \%$ \\
\hline used both behavioral approaches and & 168 & 60 & 17 & 33 & 58 \\
\hline prescribed medicine & $100 \%$ & $35.8 \%$ & $10.1 \%$ & $19.6 \%$ & $34.5 \%$ \\
\hline
\end{tabular}

The assessment of the SCC results association with the TA degree estimated by the Fagerström test shows that the probability to achieve a positive result for patients with TA Fagerström-test score 5 or more was almost significantly less, OR 0.66 (95\% CI 0.41-1.06), than that for patients with a score of 1-4 points (Table 2).
Data on the assessment of the association of SCC results with existence and outcome of previous quit attempts in the patients' smoking history show that the existence of a previous quit attempt increases the probability for a positive result in the last quit attempt. In particular, the probability to achieve a positive result of SCC was 3.71 times higher (95\%CI: CI 1.70- 
8.12) for patients who had quit for some period in a previous attempt, in comparison with those who had no results in the previous quit attempt.

The probability of an SCC positive result rises significantly with increasing level of personal motivation and readiness to stop smoking, measured in points by the special questionnaire test. In particular, the probability to achieve a positive result of SCC was 4.3 times higher for patients with 15 or more points for the level of motivation to stop smoking than that of patients with less than 11 points, $\mathrm{OR}=4.3$; 95\% CI 1.8510.00 (Table 2).

In the analysis of the association of SCC results with smokers' adherence to SCC recommendations and medication, the relevant data were used only concerning 443 patients, as 81 patients, not having made any attempts to stop smoking, were excluded from this analysis. All patients who made attempts to stop smoking after SCC were divided into 4 groups: 1) patients who did not carry out any recommended methods on SC and tried to stop smoking only by willpower, 2) patients who used only cognitive-behavioral approaches, 3) patients who used only prescribed medicine, and 4) patients who used both cognitive-behavioral approaches and prescribed medicine. Data regarding SCC results for these 4 groups are presented in the Table 3 . In the group of patients who did not carry out any recommended methods of SC only $28.5 \%$ succeeded to stop smoking for 1 month or more, in the group using only cognitive-behavioral recommendations $40.2 \%$, and in the group using only prescribed medicine $43.4 \%$, while in the group of patients who used both cognitive-behavioral recommendations and prescribed medicine it was $54.1 \%(\mathrm{p}<0.001)$.

\section{DISCUSSION}

The majority of regular smokers should be considered as patients with an addictive disease and need professional counselling and assistance to quit tobacco use. This study analyzed the SC success rate among patients who had received professional SCC in Moscow.

There are many studies that have provided the evaluation of different methods of SC aid and assistance. However, a disadvantage in most such studies is the short-term follow-up of the patient after SC assistance, and hence a correspondingly short-term success rate of SC, which is used as a criterion for efficiency of any SC aid. Many smokers manage to stop smoking for a short term, a few days to weeks. At the same time TA is very disposed to a relapse and the vast majority of patients who stopped smoking for such terms return to regular smoking $^{7,9}$. Therefore, SC for such short periods cannot be considered as effective treatment of TA. More evidential and objective criteria of SC aid effectiveness are SC terms of 3,6 and 12 months $^{10}$. This study was conducted to investigate the efficacy of qualified SCC and the factors associated with its success when the final follow-up review was made no less than 6 months afterwards.

For objective assessment of the efficacy of any kind of SC aid all variants of possible results should be considered, from the absence of any result to a successful complete SC for a long term. Out of 524 smokers included in the study, about $15 \%$ did not even attempt to stop smoking after receiving SCC. The more typical causes of refusal to try and stop smoking were a low level of motivation and readiness to practical performance of SC, a 'contemplation' stage of smoking-behavior change ${ }^{11}$. Such smokers visited SC services often out of curiosity rather than because of a serious intention to quit smoking. Of the patients, $19 \%$ who had received SCC tried to stop smoking but without any results.

Within our study, most of the patients who had received SCC did achieve some results. In particular, 19\% of smokers cut down the number of cigarettes per day by more than half. This outcome should be taken into consideration as an SCC result, since such significantly reduced smoking intensity reassures these smokers of their ability to control smoking behavior and to keep a low intensity of smoking indefinitely or even quit smoking in the future ${ }^{12}$. More than $46 \%$ of smokers completely stopped smoking for different terms, including $24 \%$ who stopped smoking for 6 months or more. These results agree with the results of similar studies given in the literature ${ }^{13,}$ 11, 15. According to the results of the NHS Stop Smoking Service in England, at the 4-week follow-up after SC assistance $50 \%$ of people successfully quit ${ }^{14}$, and at the 6-month followup after the quit date $23 \%$ of patients did not start smoking ${ }^{16}$. SC assistance conducted with hospitalized patients, as usual, has a higher success rate ${ }^{14,17,18}$.

It is known that many different factors and characteristics may be determinants of smoking behavior and cessation ${ }^{19}$. This study has identified several factors that can have a significant influence on SC results. The percentage of all men who quit smoking for more than a month was notably higher than the corresponding percentage of women. Though, in the studied cohort of smokers this difference does not reach statistical significance. These data are consistent with those of other studies that show a lower efficiency of TA treatment for women in comparison with men ${ }^{20}$. In particular, it was indicated in the report of the NHS Stop Smoking Service in England that the percentage of successful quit smoking attempts in all age groups was higher amongst men than in women ${ }^{14}$. However, 
another study found convincing evidence that men in general are not more successful in smoking cessation than women ${ }^{21}$.

The present study also revealed that the percentage of men and women, who successfully quit, at 1 month or more follow-up, was higher in the younger group of patients $(<30$ years) compared to the senior age group ( $>49$ years). The association of SC results with the age has already been noted in other studies and sometimes with different evaluations ${ }^{19,23}$. It should be noted that such an association of SC result with age, as in this study may be possible only amongst patients motivated to stop smoking and who visit SC services. Thus, younger smokers with less TA more often successfully quit in comparison with senior smokers who have longer duration of regular smoking and a greater degree of TA.

The assessment of the association between the degree of TA measured by a Fagerström test and the result of the SCC shows that in subgroups of smokers the percentage of patients who successfully quit notably decreases with increasing TA degree. The significance of TA degree for efficiency of TA treatment has been already repeatedly specified in earlier literature. Moreover, some authors consider nicotine dependence as a major factor in predicting long-term cessation ${ }^{7,12,22,23}$.

The role of smoking cessation history is also significant as a determinant of SCC outcome. Results of this study show that existence of previous attempts to quit smoking, in personal smoking history, increases the probability of SC success. The better the result of a previous attempt to quit; the more effective the latest attempt. Thus, patients who in the past could significantly reduce the number of cigarettes smoked or could stop smoking for different terms achieved smoking cessation much more often in comparison with those who had an unsuccessful previous attempt. The dependence of the result of the last quit attempt on the existence of an earlier attempt to quit has been indicated in earlier studies ${ }^{24}$. It was found that the efficiency of the next attempt increased if the previous attempt was rather recent, no more than a year ago, and some success had been achieved ${ }^{12,25,24}$. But the likelihood of achieving sustained abstinence was reduced for smokers with a failed quit attempt within the last year ${ }^{25}$. Hence, it follows that a relatively recent successful quit attempt can increase motivation to stop smoking and to repeat the quit attempt. It is known that many former smokers finally quit after two or more attempts ${ }^{23}$.

This study confirms also that patients who followed all SCC recommendations achieved better results compared to the patients who did not follow any recommendations. Thus, the adherence to professional recommendations for SC should be considered as a significant determinant of the SC result ${ }^{26}$.
This study revealed that the association of the SCC outcome with the level of motivation and readiness for SC, measured by a special questionnaire test ${ }^{8}$, was the strongest one. In the subgroup of smokers with the highest level of motivation to quit, the probability of successful SC was 4 times more than in the subgroup of patients with the minimum level of motivation. These data reinforce the assertion that motivation and willingness to quit is the most significant determinant and predictor of smoking cessation ${ }^{15,18}$. The level of motivation to quit should be considered as a fundamental factor and predictor for the success of any kind of SC aid. The level of motivation to quit can determine the SCC result association with other factors, such as age, experience of SC, adherence to SCC recommendations and TA treatment ${ }^{15,28}$. It is known that the level of motivation to quit in the population of smokers can significantly differ ${ }^{10,11}$. The majority of smokers understand that tobacco smoking is harmful to their health and it is better to quit, but at the same time many of them have doubts and questions like: 'To which degree is it harmful to me? Will I be able to live without smoking, which gives me a certain «comfort» in life? Can I overcome my TA?'. Many smokers who in the past have already tried to quit without any success have doubts about their ability to quit. Smokers with a small intensity of smoking (less than 10 cigarettes per day) are often convinced that their smoking is harmless, and therefore it is not necessary to quit ${ }^{27,29}$. All these smokers need a qualified consultation to remove doubts and questions concerning their smoking and motivation to quit.

\section{Limitations}

There are several limitations to this study. Statistical analysis was not highly qualitative because only descriptive statistics with chi-square test and bivariate analyses of sample characteristics were carried out and results were presented as unadjusted OR at $95 \%$ CI. Multivariate logistic-regression analysis to identify factors that can be associated with the SCC outcomes was not performed in comparing groups with different SCC outcomes. Furthermore, the objective assessment of the SC procedure and smoking status by self-report, through telephone calls, was also relatively limited.

\section{CONCLUSIONS}

Most regular smokers need special aid for SC. Such qualified aid must include three main components: provide knowledge about tobacco intoxication, tobacco addiction, and consequences; provide personal motivation to quit smoking; and recommend therapy for TA, including behavioral technics, medicine and other methods. This qualified aid can increase 
the probability of a successful SC by three and more times ${ }^{12,30}$. At the same time, the need for various components of the aid and their extent, can significantly differ between smoking individuals, depending on personal smoking characteristics and determinants of SC effectiveness. Therefore, a special examination of smoking history and status, degree of TA, knowledge about harmful consequences of smoking, existence and stage of motivation to quit smoking, must precede the SC aid. Based on the data obtained, the character and extent of the individualized SC aid is determined ${ }^{10}$. Consideration of individual peculiarities of smoking behavior, and the main determinants of the SC results, can significantly increase efficiency of professional SC aid and make it more rational.

We identified that the outcome of SC aid is determined mainly by the balance of two main independent determinants; level of motivation and TA degree. All other factors like age, sex, personal characteristics, form and methods of the aid, are secondary or minor. Furthermore, the main determinants have larger value for the SC assistance effectiveness than form and methods of this assistance. First of all, the level of motivation should be necessarily considered at an evidence-based tobacco cessation service. It will make this kind of medical aid more personalized and effective.

\section{REFERENCES}

1. E Renterial E, Jha P, Forman D1, Soerjomataram I. The impact of cigarette smoking on life expectancy between 1980 and 2010: a global perspective. Tob Control 2016, 25: 551-557. doi: 10.1136/tobaccocontrol-2015-052265

2. Global Adult Tobacco Survey. (GATS). Russian Federation 2009. Country report.

3. Marques P., Suhhrek M., McKee M., Rocco L. Adult health in the Russian Federation Health Affairs. 2007; 26 (4): 1040-51. doi: 10.1377/hlthaff.26.4.1040

4. Zaridze D., Karpov R., Kiselev S., et al. Smoking is the basic cause of mortality in Russia. Journal of RAMS 2002, 9: 40-45.

5. Federal law RF "About the protection of the health of citizens from the action of that surrounding tobacco smoke and the consequences of the consumption of tobacco" from 23.02.2013 No15-FL.

6. WHO Framework Convention on Tobacco Control. World Health Organization. Geneva. Switzerland. 2003.

7. Fagerström KO., Schnider NG. Measuring nicotine dependence: a review of the Fagerström Tolerance Questionnaire. J Behav Med 1989, 12: 159-182. doi: 10.1007/bf00846549

8. Levshin V.F. Test for the motivation evaluation to giving up smoking and its practical application. Voprosy Narkologii Journal 2003, 6: 48-53.

9. Ballard J., Kreiter K.T., Claassen J. et al. Risk factors for continued cigarette use after subarachnoid hemorrhage. Stroke. 2003, 34 (8): 1859-63.

doi: 10.1161/01.str.0000080522.36041.9f
10. Levshin V.F. Tabakizm. Patogenez, diagnostika \& treatment. IMApress. Moskow - 2012, C.125. Available at: www.ima-press.net (accessed February 2017).

11. Prochaska J.O., Velicer W.F., DiClemente C.C., Fava J. Measuring process of change: applications to the cessation of smoking. J.Consult. Clin. Psychol 1988. 56: 520-8.

doi: 10.1037//0022-006x.56.4.520

12. West R., Brown J. Smoking and Smoking Cessation in England 2011. London. April 2012 Available at: www.smokinginengland.info (accessed February 2017).

13. Phaik Yuan Poh., Celine Chang Chyi Ng. A 4-year Follow-up Evaluation Of A Pharmacist-managed Smoking Cessation Programme With Emphasis On Effectiveness Of Different Treatment Modalities Tob Prev Cessation 2016, 2: p73.

doi: $10.18332 /$ tpc/65822

14. Statistics on NHS Stop Smoking Services in England. Health \& Social Care Information Centre. Publication date: January 13, 2016.

15. Toljamo T., Kaukonen M., Nieminen P., Kinnula VL. Early detection of COPD combined with individualized counseling for smoking cessation. Scand J Prim Health Care. 2010, 28(1):41-46. doi: 10.3109/02813431003630105

16. Natalie Walker, Colin Howe, Chris Bullen et al. The combined effect of very low content cigarettes, used as adjunct to usual Quitline care on smoking cessation; a randomized controlled trial. Addiction 2012, 107 (10):1857-67. doi: 10.1111/j.1360-0443.2012.03906.x

17. Brunner Frandsen N., Sorensen M., Hyldahl TK., Henriksen RM., Bak S. Smoking cessation intervention after ischemic stroke or transient ischemic attack: a randomized controlled pilot trial. Nicotine Tob Res 2012, 14: 443-447. doi: $10.1093 / \mathrm{ntr} / \mathrm{ntr} 233$

18. Ha E, Jo JY, Ahn AL, et al. Predictors of Successful Smoking Cessation after Inpatient Intervention for Stroke Patients. Korean J Fam Med 2016, 37(2): 85-90. doi: $10.4082 / \mathrm{kjfm} .2016 .37 .2 .85$

19. Van Loon A.J.M., Tijhuis M., Surtees P., Ormel J. Determinants of smoking status: cross-sectional data on smoking initiation and cessation. The Europen Journal of Public Health 2005, 15 (3): 256261. doi: 10.1093/eurpub/cki077

20. Ostbye T., Taylor DH. The effect of smoking on years of healthy life. Health Serv Res 2004, 39 (3): 531-52. doi: 10.1111/j.1475-6773.2004.00243.x

21. M. Jarvis., J. Cohen., C. Delnevo., G. Giovino. Dispelling myths about gender differences in smoking cessation. Tob Control 2012, 22: 356360 . doi: 10. 1136/tobaccocontrol-2011-50279

22. Parks T., Wilson C., Turner K., Chin J. Failure of hospital employees to comply with smoke-free policy is associated with nicotine dependence. BMC Public Health 2009, 9: 238.

doi: 10.1186/1471-2458-9-238

23. Hyland A., Li Q., Bauer J., Giovino G. Predictors of cessation in a cohort of current and former smokers followed over 13 years. Nicotine \& Tobacco Research 2004, Vol. 6, Suppl. 3, Pages: S363 S369.

doi: 10.1080/14622200412331320761

24. Jacques Donze, Ruffieux C., Cornuz J. Determinants of smoking and cessation in older women. Age and Ageing 2007, 36 (1): 53-57. 


\section{Research paper}

doi: 10.1093/ageing/afl120

25. Partos T.R., Borland R., Yong H., The Quitting Rollercoaster. Nicotine Tob Res 2013, doi: 10, 1093/ntr/ntt025

26. Cropsey KL, Clark CB., Stevens EN. et al. Predictors of medication adherence and smoking cessation among smokers under community corrections supervision. Addict Behav 2016, 65:111-117.

doi: 10.1016/j.addbeh.2016.10.010

27. Smit E., Fidler J., West R. The role of desire, duty and intention in predicting attempts to quit smoking. Addiction 2011,106(4): 844-51. doi: 10.1111/j.1360-0443.2010.03317.x.

28. Soares de Azevedo R., Frnandes R. Factors relating to failure to quit smoking. Sao Paulo Med.J 2011, vol.129 no.6 Dec.

doi: 10.1590/s1516-31802011000600003

29. Darlow S., Lobel M. Smoking behavior and motivational flexibility in light and heavy smokers. Addict Behav 2012, 37(5):668-73.

doi: 10.1016/j.addbeh.2012.02.001

30. Fiore MC., Bailey WC., Cohen SJ., et al. Treat in Tobacco Use and Dependence: Clinical Practice Guideline. Rockville, MD. United States Department of Health and Human Services, Public Health service. 2000.

CONFLICT OF INTERESTS

The authors have completed and submitted the ICME Form for Disclosure of Potential Conflicts of Interest and none was reported.

FUNDING

There was no source of funding for this research.

PROVENANCE AND PEER REVIEW

Not commissioned:

externally peer reviewed 